\title{
Plasticity of Memory for New Learning in Very Old Age: A Story of Major Loss?
}

\author{
Tania Singer, Ulman Lindenberger, and Paul B. Baltes \\ Max Planck Institute for Human Development
}

\begin{abstract}
Longitudinal survivors of the Berlin Aging Study $(N=96$, mean age $=84$ years, range $75-101$ years $)$ were instructed and trained in a mnemonic skill to examine plasticity of episodic memory performance in very old age. Performance gains after mnemonic instruction were modest, and most individuals were unable to further enhance their performance during 4 sessions of mnemonic practice. Whereas the proportion of variance explained by measures from the broad fluid-ability domain (e.g., perceptual speed) increased with training, the proportion of variance explained by crystallized-ability domain (e.g., word knowledge) and sociobiographical variables decreased. Furthermore, prior 6-year longitudinal changes (loss) in perceptual speed predicted individual differences in plasticity. Results suggest that aginginduced biological factors are a prominent source of individual differences in cognitive plasticity in very old age.
\end{abstract}

Individuals above 75 years of age represent the fastest growing segment of the older adult population in developed Western countries (see Bäckman, Small, Wahlin, \& Larsson, 2000; Vaupel et al., 1998). However, research on the age segment above 75 years, the so-called fourth age (cf. M. M. Baltes, 1998) or the very old (cf. Bäckman et al., 2000), is rather scarce (but see P. B. Baltes \& Mayer, 1999; Schaie \& Willis, 1986; Willis \& Nesselroade, 1990; Yesavage, 1983; Yesavage, Sheikh, Friedman, \& Tanke, 1990). Relevant research mainly focused on the young old (the age range between 60-80 years). For instance, with respect to training studies, two meta-analyses (Stigsdotter Neely, 1994; Verhaeghen, Marcoen, \& Goossens, 1992) based on 33 and 38 memory training studies, respectively, reported a mean age of 69 years, with ranges from 61 to 78 years.

Because of the lack of research on cognitive plasticity in very old age, the first objective of the present study was to investigate the amount and limits of cognitive plasticity in participants over 75 years of age. Specifically, we investigated cognitive plasticity in episodic memory using the Method of Loci (MoL). Typically, this

Tania Singer, Ulman Lindenberger, and Paul B. Baltes, Center for Lifespan Psychology, Max Planck Institute for Human Development, Berlin, Germany.

The present research was part of a doctoral thesis conducted at the Max Planck Institute for Human Development. Special thanks go to Anna Mallau, Andreas Wand, Astrid Meyer, Dorothea Schrader, and Julia Gerlach for their assistance with data collection; to Berndt Wischnewski, Martin Wehrmann, and Stefan Peetz for technical assistance; to Paolo Ghisletta and to Paul Verhaeghen for their help and comments on a version of this article; and to all our study participants for their participation in this effort-requiring study.

Correspondence concerning this article should be addressed to Tania Singer, who is now at the Wellcome Department of Imaging Neuroscience, 12 Queens Square, WC1N 3BG London, England; Ulman Lindenberger, who is now at Department of Psychology, Saarland University, D-66123 Saarbrücken, Germany; or Paul B. Baltes, Max Planck Institute for Human Development, Lentzeallee 94, D-14195 Berlin, Germany. E-mail: t.singer@fil.ion.ucl.ac.uk, lindenberger@mx.uni-saarland.de, or sekbaltes@ mpib-berlin.mpg.de mnemonic technique does not belong to the behavioral repertoire of individuals (e.g., Park, Smith, \& Cavanaugh, 1990). Thus, the emphasis of the present study was on "new learning" rather than on maintenance or improvement of cognitive skills acquired in the past. Our second objective was to determine ontogenetic antecedents of memory plasticity for new learning in very old age. Measures of current intellectual status and measures of past 6-year longitudinal changes in intellectual functioning were included for this purpose. With the notable exception of training studies in the context of the Seattle Longitudinal Study (Schaie, 1996; Schaie \& Willis, 1986; Willis \& Nesselroade, 1990), the relationship between long-term longitudinal change in cognitive functioning and short-term learning-based change has not been the focus of empirical investigations.

In behaviorally oriented cognitive aging research, plasticity or within-person variability (e.g., P. B. Baltes \& Lindenberger, 1988; P. B. Baltes \& Willis, 1982) usually refers to learning gain (e.g., pretest-posttest difference scores); to levels of performance after instruction and practice in performance-enhancing skills, strategies, or techniques; or to both (P. B. Baltes, 1987). Two major results emerge from memory training research using techniques such as the MoL, the name-face mnemonic, or the pegword mnemonic (for memory training studies, see Verhaeghen et al., 1992; for training programs in fluid intelligence, see P. B. Baltes \& Lindenberger, 1988; Schaie \& Willis, 1986). First, instruction or instruction and practice in a mnemonic technique lead to considerable performance improvements in healthy older adults (for overviews, see Camp, 1998; Stigsdotter Neely, 1994; Verhaeghen et al., 1992). Second, younger adults benefit more from memory training programs than older adults; that is, preexisting age differences are magnified through mnemonic training (Kliegl, Smith, \& Baltes, 1990; Rebok \& Balcerak, 1989; Rose \& Yesavage, 1983; Thompson \& Kliegl, 1991; Verhaeghen \& Marcoen, 1996). Agerelated reductions in plasticity are observed between groups of young and young-old adults as well as within samples of older adults (Verhaeghen et al., 1992). In summary, these findings suggest that normal aging is associated with a reduction but not 
with a complete loss of cognitive plasticity in episodic memory performance (Kliegl et al., 1990).

The present study examined whether this basic pattern of results also applies to very old age. In continuation of previous testingthe-limits studies (P. B. Baltes \& Kliegl, 1992; Kliegl \& Baltes, 1987; Kliegl et al., 1990), participants were instructed and trained in MoL, with the goal to approximate upper limits of plasticity. Given marked functional decrements in the very old (Bäckman et al., 2000; Lindenberger \& Baltes, 1997), our first goal was to investigate the extent to which the potential to acquire and the potential to further refine the use of a new mnemonic technique are preserved in very old age.

Our second objective was to link individual differences in plasticity to individual differences in intellectual abilities and sociobiographical factors. Here, our predictions were based on two types of data: (a) measures taken in close temporal proximity to the training study (e.g., just before training) and (b) longitudinal measures reflecting 6-year changes prior to the onset of training. On the basis of general assumptions about testing-the-limits and dynamic testing procedures (e.g., M. M. Baltes \& Kindermann, 1985; Carlson \& Wiedl, 1978; Grigorenko \& Sternberg, 1998; Guthke, 1992; Kliegl \& Baltes, 1987), we expected that the magnitude and patterns of predictive relations would change in the course of skill acquisition. Specifically, we predicted that instruction and extensive practice would induce the use of more general cognitive resources indexed by measures from the broad fluidability domain (cf. Horn, 1989) while reducing the role of background and task-specific factors such as familiarity with memory strategies or with the test situation. Following two-component models of intelligence (e.g., P. B. Baltes, 1987; Cattell, 1971; Horn, 1989), we therefore expected the predictive power of markers of the broad fluid-ability domain to increase during instruction and practice, whereas markers of the crystallized-ability domain and related sociobiographical variables were expected to decrease. More specifically, we used measures of perceptual speed and knowledge as markers of the broad fluid and crystallized domains, respectively (see also Lindenberger \& Baltes, 1997). Even though memory was originally conceptualized as a second marker of the broad fluid-ability domain and fluency as a second marker of the broad crystallized-ability domain (e.g., Lindenberger \& Baltes, 1994), we decided to base our predictions on the two most prototypical and nonambiguous markers; namely, perceptual speed and knowledge. Given the nature of the criterion task, we assumed that measures of memory functioning would primarily be associated with MoL memory measures through domain-specific, task-related mechanisms and less through domain-general, age-related processes. With regard to fluency, we assumed that although performance certainly draws on the semantic knowledge base, it also relies heavily on executive and speeded retrieval processes (see also Salthouse, 1993). Hence, fluency may therefore be better characterized as a fluid-crystallized hybrid (cf. Lindenberger \& Baltes, 1997; Mayr \& Kliegl, 2000). In line with this assumption, analysis of longitudinal change in cognitive functioning in BASE gives evidence for marked decline in speed, memory, and fluency; whereas knowledge evinces long-life stability (Singer, Verhaeghen, Ghisletta, Lindenberger, \& Baltes, 2003).

The second set of correlational predictions concerned the relation between prior long-term longitudinal change and later shortterm learning. On the basis of general developmental theories (e.g., P. B. Baltes, Reese, \& Nesselroade, 1988; Karmiloff-Smith, 1992), specific theorizing on the relation between macrogenetic and microgenetic change (e.g., Lindenberger \& Baltes, 1995; for similar reasoning in the domain of pathological functioning, see M. M. Baltes \& Baltes, 1997) and the dynamic systems theory (e.g., Elman et al., 1996, chapter 4), we made two predictions. First, we assumed that ontogenetic trajectories contain plasticity-relevant information. Specifically, individuals with greater longitudinal losses in task-relevant intellectual abilities were expected to show lower gains in mnemonic performance. Second, we hypothesized that prior ontogenetic change contains plasticity-related information over and above concurrent measures of baseline performance. To illustrate the latter prediction, imagine two individuals: A and B. Six years prior to mnemonic training, A shows higher levels of task-relevant cognitive performance than B. However, during the longitudinal observation period, A suffers greater age-associated decline than B, and they end up at identical performance levels immediately prior to training. Although their levels of task-related intellectual performance are identical at baseline, A and B are on markedly different ontogenetic paths. We predicted that short-term learning, as a marker of cognitive plasticity, would uncover these differences.

\section{Method \\ Sample}

The very old sample consisted of 96 participants ( 58 women and 38 men, mean age $=84, S D=4.8$, range $=75-101$ years). The young comparison sample consisted of 20 adults ( 9 women and 11 men, mean age $=24.7$, $S D=4.8$, range $=21-29$ years). Older adults were paid 350 Deutsche Mark (DM; approximately U.S. \$175) for participating in the eight sessions of the training study. Young adults were paid 160 DM (approximately U.S. $\$ 80)$ or $20 \mathrm{DM}$ per session.

\section{Very Old Adult Sample}

Participants were recruited from BASE, a longitudinal and multidisciplinary study on very old age and aging (P. B. Baltes \& Mayer, 1999). The parent sample of BASE $(N=516)$ originated from a random draw of addresses from the general registry of Berlin (West) and was stratified by age and gender (for more information, see P. B. Baltes \& Mayer, 1999).

The present sample was based on 126 (of 516) individuals who survived the 6-year time span of BASE $(N=239)$, had participated in the fourth measurement occasion of BASE (1997-1998), and had given their consent to be contacted for subsequent investigations. Five individuals (4\%) with a clinical diagnosis of moderate or severe dementia (Diagnostic and Statistical Manual of Mental Disorders-Revised; DSM-III-R; American Psychiatric Association [APA], 1987) obtained at the third measurement occasion of BASE (1995-1996) were excluded from the present sample. ${ }^{1}$ Another five individuals could not be contacted, 13 individuals (10\%) refused to participate in the training study, and 7 individuals $(6 \%)$ did not complete the present study because of health problems. The resulting study sample consisted of 96 participants (58 women and 38 men; mean age $=84, S D=4.8$; age range $=75-101$ years). Of these 96,2 resided in

\footnotetext{
${ }^{1}$ Individuals with a diagnosis of mild dementia were not excluded, given the low validity and reliability of dementia diagnoses in the very-mild-tomild range. Three persons $(3 \%)$ were diagnosed as mildly demented (DSM-III-R; APA, 1987) at $\mathrm{T}_{3}$. The decision not to exclude these individuals from the present sample was corroborated by the observations that (a) these individuals had MMSE scores of 21, 26, and 26 and (b) they showed "normal" learning ability in the context of mnemonic training (learning gain $=2.50,3.50,4.75$ words, respectively).
} 
long-term care facilities, 9 lived in homes for seniors, and the remaining 85 lived in their own homes. Forty-nine percent of the sample had primary level education (Volksschulabschluss; comparable to a junior-high school degree), $41 \%$ lower secondary level (Realschule; comparable to high school), and $10 \%$ upper secondary level (Abitur; comparable to two years of college and more). On average, participants had 11.4 years of education ( $S D=2.3$, range $=8-17$ years). This value approximates the level of education observed in the BASE parent sample $(N=516$; mean education $=11.0$ years, $S D=3.0$ ). In the Mini Mental State Examination Test (MMSE; Folstein, Folstein, \& McHugh, 1975) administered prior to mnemonic training, the sample had a mean MMSE score of 27.3 points $(S D=2.15$, range $=21-30$ points), corresponding to values observed in healthy, normal nonclinical samples of older adults (e.g., Folstein et al., 1975).

\section{Younger Adult Sample}

Given that much is known about the acquisition curves of young adults, our main goal in recruiting a sample of younger adults was to replicate earlier findings and obtain an estimate of the size of age-related reductions in plasticity from young to very old age (Kliegl et al., 1990). Therefore, only a small sample of younger adults $(n=20$, mean age $=24.7$ years, range $=21-29$ years) was recruited. Students of psychology were excluded to reduce the probability of preexperimental familiarity with mnemonic techniques. From the original sample of young participants, 1 dropped out for lack of interest, thus resulting in an effective sample of 20 younger adults. The level of education was higher in the young group than in the very old group. Thus, $15 \%$ of the young adults had lower secondary level education, $75 \%$ had upper secondary level education, and 10\% had completed a university degree. Thus, age comparisons reported in the present study may be biased against older adults.

\section{Design and Procedure of Training Study}

The training program comprised a total of eight 1-2 hr sessions, scheduled 1 week apart (see Table 1). The entire experimental study extended over a period of 1 year (1998-1999). For BASE participants, average participation duration was 1.7 months $(S D=0.35)$, and training took place in individualized sessions at home. Young adults were tested in small groups at the Max Planck Institute for Human Development. ${ }^{2}$

At the beginning of the first session (pretest), baseline memory performance was assessed. At the end of the first session and throughout the second session, participants were instructed in MoL. Instruction effects were assessed at the third session (Posttest I). The next four sessions (Sessions 4-7) were practice sessions in which adaptive-testing procedures were used. Practice effects were assessed at Session 8, the last session (Posttest II)

\section{Apparatus and Material}

Stimuli for memory tests and practice trials were presented on an Apple Macintosh SE/30. Lists of words originated from a pool of 1,387 words derived from a German dictionary and were rated by two independent raters as being high in imagery (e.g., values of 6 or 7 on Likert scales of imageability and concreteness; cf. Paivio, Yuille, \& Madigan, 1968). Imagery ratings provided from the norms by Baschek, Bredenkamp, Öhrle, and Wippich (1977) existed only for a subsample of nouns, with imageability and concreteness ratings of 6 or 7 . The 763 nouns used in the present study were selected from the initial pool of 1,387 by two other independent raters. Selection was based on the following criteria: similar word length, absence of potentially emotion-eliciting words (e.g., gun), and high familiarity in both cohorts. During the entire study, each word was presented only once.

Thirty-two well-known Berlin landmarks constituted the mental location map for the MoL mnemonic. The sequence of locations corresponded to a
Table 1

Overview of Study Design

\begin{tabular}{|c|c|}
\hline Measurement occasion & Type of assessment \\
\hline \multicolumn{2}{|c|}{$\begin{array}{l}\text { Assessment of predictor measures in the Berlin Aging Study } \\
\qquad(1990-1998)\end{array}$} \\
\hline First occasion $1990-1993\left(\mathrm{~T}_{1}\right)$ & $\begin{array}{l}\text { Cognitive Battery } \\
\text { Social Class Index, } \\
\text { years of education }\end{array}$ \\
\hline Fourth occasion 1997-1998 $\left(\mathrm{T}_{4}\right)$ & $\begin{array}{l}\text { Cognitive Battery } \\
\text { Income }\end{array}$ \\
\hline
\end{tabular}

\begin{tabular}{lll}
\hline Phase & Session & Type of assessment \\
\hline
\end{tabular}

Assessment of outcome measures in the training study (1998-1999)

\begin{tabular}{|c|c|c|}
\hline Pretest & 1 & $\begin{array}{l}\text { Baseline memory performance (with } \\
\text { four word lists), Mini Mental State } \\
\text { Examination Test, and } \\
\text { demographics }\end{array}$ \\
\hline Instruction & 1,2 & Instruction in the MoL \\
\hline Posttest I & 3 & $\begin{array}{l}\text { Test session: MoL with four word lists } \\
\text { Assessment of strategy use (self and } \\
\text { external ratings) }\end{array}$ \\
\hline Practice I-IV & $4,5,6,7$ & $\begin{array}{l}\text { Adaptive practice sessions (with six } \\
\text { word lists each) } \\
\text { Assessment of strategy use (external } \\
\text { ratings) }\end{array}$ \\
\hline Posttest II & 8 & $\begin{array}{l}\text { Test session: MoL with four word lists } \\
\text { Assessment of strategy use (self and } \\
\text { external ratings) }\end{array}$ \\
\hline
\end{tabular}

Note. The time between the first and fourth measurement occasions of the Berlin Aging Study was, on average, 6.03 years, and between T4 and beginning of the training study was, on average, 6.43 months. MoL $=$ Method of Loci; $\mathrm{T}=$ Time

geographically plausible sightseeing tour through Berlin. To prevent incorrect responses reflecting failures to retrieve landmarks in correct order, landmark cues were presented at both encoding and retrieval. Stimulus materials were presented bimodally (auditory and visually) to compensate for low hearing, vision, or both. The visual material was presented in large black letters (font $=$ Geneva; size $=38$ points) on white background . Auditory stimuli were presented through headphones. Location cues and stimulus words were spoken by two different male voices respectively (professional radio speakers). The volume was adjusted individually at the beginning of each session. Visual presentation of the location cue was followed by auditory presentation of the location cue (interstimulus interval $[$ ISI] $=600 \mathrm{~ms}$ ). After $1 \mathrm{~s}$, the visually presented target word appeared on the screen followed by the auditory stimulus presentation (ISI $=600$ $\mathrm{ms})$. Location cue and target word remained visible on the screen for another $10 \mathrm{~s}$. After an ISI of $12 \mathrm{~s}$, the next location cue appeared. Presentation rate was held constant throughout the entire study, with an interval of $12 \mathrm{~s}$ per word. Responses were given verbally and entered by the experimenter on a keyboard.

\footnotetext{
${ }^{2}$ According to Verhaeghen et al. (1992), performance gains that are due to mnemonic training are generally stronger when individuals are tested in groups rather than in individualized sessions. However, the Verhaeghen et al. meta-analysis did not include very old individuals. For two reasons, individualized testing was preferable with very old research participants. First, many of the participants in very old age could not leave their homes because of health problems or other reasons. Second, individualized tutoring allowed for more adequate instruction and testing.
} 


\section{Test Sessions: Pretest, Posttest I, and Posttest II (Sessions 1, 3, and 8)}

Memory performance was tested (a) before MoL instruction (pretest, baseline performance), (b) after MoL instruction (Posttest I), and (c) after MoL practice (Posttest II). At each test session, two 8-word lists and two 16-word lists were administered, in that order. With a total of 32 location cues arranged as a round trip, this implies that the first 16 locations of the round trip were repeated while participants were learning the last list.

\section{Procedure of Instruction in MoL (Sessions 1 and 2)}

MoL instruction started at the end of the first session. First, MoL was described following Bower (1970). After a historical introduction and detailed illustrations, participants practiced the technique with a list of three words. At the second session, participants were shown an album with color photographs of each of the 32 Berlin landmarks in correct order and were asked to report their memories and associations about these locations. Next, they practiced MoL use with four lists of six words each. The first two lists were self-paced, and the last two lists were presented at $12 \mathrm{~s}$ per word. Participants were encouraged and trained to think aloud during the encoding phase. Specifically, they were instructed to report whatever they were thinking or mentally seeing while encoding the location-word pair. Note that we did not assess ratings of strategy utilization behavior in the comparison group of young participants who were tested in small groups and, therefore, they did not think aloud during encoding. We cannot rule out that the demand of thinking aloud may have been disadvantageous for the very old participants. However, observations from a pilot study with 10 participants aged 80 and above suggested the opposite. Both the tutors and the participants reported that thinking aloud actually facilitated and enhanced MoL memory performance because it prevented task-extraneous intrusive thoughts, helped to focus attention to the task, and served as a constant reminder to use interactive images. These preexperimental observations led us to choose a thinking-aloud format for the very old participants.

\section{Procedure for Adaptive Practice of Mnemonic Skill} (Sessions 4, 5, 6, and 7)

Adaptive practice was used to (a) promote learning, (b) assess differences in learning (optimization), (c) approach performance limits (e.g., asymptotic maxima), and (d) allow age comparison in learning between young adults and very old participants.

Each of the four adaptive practice sessions comprised six lists of words presented at $12 \mathrm{~s}$ per word. The practice sessions were adaptive in the sense that the number of words in each list was adapted according to the participant's recall performance on prior lists. Starting with the best performance displayed on one of the lists at Posttest I (i.e., a maximum of 16 words), list length was increased by 1 word when errorless performance was achieved. If participants failed to reach $75 \%$ correct twice in immediate succession, list length was reduced by 1 word for the next list. At subsequent practice sessions, starting levels were determined by the best performance in the previous practice session.

With regard to the sequence of the presented location cues, a given list started with the location on the roundtrip through Berlin that followed the location used as the last cue on the preceding list. Thus, a given location was repeated for the first time after 32 nouns. After each list, participants received feedback about the number of words correctly recalled. Specifically, the computer displayed the landmarks, the to-be-remembered nouns, and the responses of the participant. Throughout practice, participants were encouraged to use the mnemonic.

\section{Covariates From the Berlin Aging Study}

Covariates were taken from the first $\left(\mathrm{T}_{1}\right)$ and at the fourth $\left(\mathrm{T}_{4}\right)$ measurement occasion of BASE (see Table 1). Two of the sociobiographical variables-social class and years of education-were assessed at $T_{1}$ (1990-1993); income was assessed at $T_{4}$ (1997-1998). Cognitive measures were assessed at both $\mathrm{T}_{1}$ and $\mathrm{T}_{4}$. We refer to performance at $\mathrm{T}_{1}$ as initial status and to performance at $\mathrm{T}_{4}$ as current status. The mean temporal time between $\mathrm{T}_{1}$ and $\mathrm{T}_{4}$ was 6.00 years $(S D=0.78)$, and the mean time between $\mathrm{T}_{4}$ and the beginning of the training study was 6.43 months $(S D=3.03$, range $=1.40-18.17$ months).

\section{Cognitive Assessment}

Intellectual functioning was assessed with a test battery informed by psychometric theory (Carroll, 1993; cf. Lindenberger, Mayr, \& Kliegl, 1993). The longitudinal cognitive battery of BASE consists of eight tests measuring four intellectual abilities: (a) perceptual speed (Identical Pictures and Digit Letter), (b) memory (Paired Associated and Memory for Text), (c) fluency (Animals and Letter $S$ ), and (d) knowledge (Vocabulary and Spot-a-Word). Following the theory of fluid versus crystallized intelligence (Cattell, 1971; Horn, 1989), speed and memory represent the broad fluid-ability domain, whereas knowledge and fluency represent the broad crystallized-ability domain (e.g., Lindenberger \& Baltes, 1997).

Specifically, the Digit Letter test resembles the Digit Symbol Substitution test of the Wechsler Adult Intelligence Scale (WAIS; Wechsler, 1955), except that participants are asked to name letters instead of writing symbols. In the Identical Pictures test, participants have to quickly select a picture from five response possibilities to match a given target picture Memory was assessed with a Paired Associate test with eight pairs of concrete nouns and a story recall test. To assess fluency, participants had to name (a) as many different words starting with the letter $S$ or (b) as many different animals as possible within $90 \mathrm{~s}$. Word knowledge was assessed with a shortened version of the vocabulary subtest of the German version of the WAIS (HAWIE; Wechsler, 1982) and a test in which participants had to choose the word in a list containing one word and four pronounceable nonwords (Spot-a-Word). For all four intellectual abilities, unitweighted linear composites of the two tests were computed. A detailed description of the tests, including their psychometric and structural properties, is found in Lindenberger et al. (1993) and Lindenberger and Baltes (1997, Table 1). To allow longitudinal comparisons, the four cognitive composites were transformed to a $T$ metric and standardized in relation to the BASE parent sample $(N=516)$.

\section{Sociological and Life-History Variables}

Three variables were used to represent life-history sociocultural status. Income was measured by net income in Deutsche Mark per month per capita (e.g., Mayer \& Wagner, 1996; Wagner, Motel, Spiess, \& Wagner, 1996). Income values were log-transformed because the original scale was highly skewed. Social class was computed by classifying participants in five classes, ranging from lower class, lower middle class, middle class, upper middle class, to high middle class (cf. Mayer \& Wagner, 1996). According to this classification, $20 \%$ of the participants belonged to the lower or lower middle classes, $68 \%$ (the majority) to the middle or upper middle classes, and $12 \%$ to the high middle class. Education refers to the number of years spent in educational settings (schooling and academic training).

\section{Strategy Use}

MoL strategy use was measured with a five-item questionnaire rated by the tutors and assessed in all sessions except for the pretest. The first item aimed at the quantitative assessment of the correct use of the mnemonic technique and asked how frequently participants used MoL during that particular session (five answer categories, ranging from "all words," "more than half of the words," "half of the words," "less than half of the words," and "not at all"; see also Verhaeghen \& Marcoen, 1996). Tutor ratings were assessed at both posttests as well as at the four practice sessions. At 
both posttests, the same questions were also presented to the participants (self-ratings). With respect to the tutor-rated frequency of strategy use, participants remained relatively stable over the training course following MoL instruction (retest stabilities across test sessions ranged from .75 to .90 , with a mean of .83). In addition, correlations between external and self- ratings at both posttests were high $(r=.80$ and $r=.70$; both $p$ s $<$ $.01)$.

\section{Statistical Analyses}

Behaviorally, memory plasticity generally refers to (a) levels of performance attained after training in posttest, which are assumed to reflect approximations to maximum performance potential (e.g., Kliegl et al., 1990) or (b) treatment gains from pre- to posttest, which are assumed to reflect the "range of intraindividual differences in memory functioning" (Verhaeghen et al., 1992, p. 242). With respect to correlational analyses of the very old sample, we follow both practices and report both Posttest II performance and treatment gains. Two types of treatment gains were computed (e.g., Cronbach \& Furby, 1970; but see also Rogosa, Brandt, \& Zimowski, 1982): (a) simple difference scores between pretest and Posttest II and (b) residualized gain scores reflecting interindividual differences in change from pretest to Posttest II controlled for differences at pretest. Simple difference scores and residualized gain scores were highly correlated in the present sample of very old adults $(r=.99)$, and the pattern of results was identical for the two scores. With regard to longitudinal change on the psychometric variables, correlations between raw $\mathrm{T}_{1}-\mathrm{T}_{4}$ difference scores and residualized gain scores also approximated 1.00 (.99 for speed, .93 for memory, .94 for fluency, .97 for knowledge, and .98 for the intelligence composite)

Throughout, alpha levels were set to .01 for mean differences and to .05 for covariation differences. This difference in alpha levels reflects differences in statistical power for detecting mean and covariation differences, respectively (e.g., Cohen, 1977).

\section{Results}

\section{Description of the Acquisition Function of Young and Very Old Adults}

\section{Effects of Instruction and Practice in MoL in the Very Old}

Means (and standard deviations) of word recall in test and practice sessions broken down by age group are summarized in Table 2. Within-session reliability scores were satisfactory for both young and very old adults; Spearman-Brown split-half (oddeven) reliability coefficients ranged between .89 at pretest and .96-.99 at the following seven sessions in the very old sample. With the exception of low correlations in both posttests that were due to ceiling effects (.78 and .63), reliability coefficients were equally high in the young comparison sample (ranging between .90 in pretest and .96 to .99 in practice sessions).

To investigate training effects in the sample of the 75 to 101year-old participants, a repeated measure analysis of variance (ANOVA) was computed with test session (pretest, Posttest I, and Posttest II) as the within-subject variable. The ANOVA revealed that memory performance increased significantly with training, $F(2,190)=231.60, M S E=2.45, p<.01, \eta^{2}=.70$. The computation of Bonferroni-adjusted contrasts between successive test sessions confirmed that performance after instruction at Posttest I was significantly higher than performance at baseline at pretest, $F(1,95)=242.89, M S E=5.43, p<.005, \eta^{2}=.72$, and that performance at Posttest II was significantly higher than per-
Table 2

Means and Standard Deviations of Memory Performance in Test and Practice Sessions Averaged Across Word Lists of a Session as a Function of Age Group

\begin{tabular}{|c|c|c|c|c|}
\hline \multirow[b]{3}{*}{ Session } & \multicolumn{4}{|c|}{ Age group } \\
\hline & \multicolumn{2}{|c|}{$\begin{array}{l}\text { Very old } \\
(n=96)\end{array}$} & \multicolumn{2}{|c|}{$\begin{array}{l}\text { Young adults } \\
(n=20)\end{array}$} \\
\hline & $M$ & $S D$ & $M$ & $S D$ \\
\hline \multicolumn{5}{|l|}{ Test sessions (fixed format) } \\
\hline Pretest (Session 1) & 3.39 & 2.29 & 10.08 & 2.08 \\
\hline Posttest I (Session 3) & 7.10 & 3.07 & 11.43 & 0.80 \\
\hline Posttest II (Session 8) & 7.97 & 3.37 & 11.75 & 0.46 \\
\hline \multicolumn{5}{|c|}{ Practice sessions (adaptive format) } \\
\hline Practice I (Session 4) & 7.54 & 4.37 & 15.88 & 2.27 \\
\hline Practice II (Session 5) & 7.14 & 4.47 & 18.07 & 2.77 \\
\hline Practice III (Session 6) & 7.39 & 4.92 & 19.99 & 3.99 \\
\hline Practice IV (Session 7) & 7.72 & 5.24 & 21.09 & 4.69 \\
\hline
\end{tabular}

Note. Scores in test sessions were based on the average performance across four word lists (maximum score $=12$ ), scores of the four adaptive practice sessions were averaged across six word lists (given perfect recall in all 24 practice lists, the maximum average number of words correctly recalled in the fourth practice session $=33.5$ ). In the group of young adults, ceiling effects were observed in the test sessions.

formance immediately after instruction at Posttest I, $F(1$, 95) $=35.56, M S E=2.04, p<.005, \eta^{2}=.27$.

As shown in Table 2, the very old increased their recall, averaged across all four word lists of a given test session, from 3.39 to 7.10 words after instruction and to 7.97 words after training. Overall, memory performance increased by two standard deviations of baseline performance: $(7.97-3.39) / 2.29=2.00 S D$. Eighty-one percent of this average performance gain, however, was already manifest at Posttest I: $(7.10-3.39) / 2.29=1.62 S D .^{3}$

\section{Memory Performance During Adaptive Practice in the Very Old}

To assess memory performance during adaptive practice sessions, the average number of words recalled per session was analyzed with a repeated measure ANOVA and with practice session (Practice I to Practice IV) as the within-subject variable (see Table 2).

Significant practice effects were observed, $F(3,285)=6.84$, $M S E=0.84, p<.01, \eta^{2}=.07$. Specification of polynomial contrasts did not yield a significant linear trend, $F(1,95)=1.81$, $M S E=1.68, p>.01$, but did yield a significant quadratic trend, $F(1,95)=27.50, M S E=0.46, p<.01, \eta^{2}=.22$. Bonferroniadjusted post hoc contrasts between successive practice sessions revealed that the quadratic trend was based on a decline of memory performance from the first to the second practice session, $F(1$, $95)=10.20, M S E=1.47, p<.003, \eta^{2}=.09$, only a marginally significant increase from the second to the third session, $F(1$,

\footnotetext{
${ }^{3}$ The reduction of performance gains from Posttest I to Posttest II may reflect ceiling effects in high-functioning research participants. To examine this possibility, we excluded all research participants who achieved a mean of 11.50 or more words at Posttest II $(n=13)$. Analyses with the reduced sample led to analogous results as analyses with the full sample.
} 
$95)=6.26, M S E=0.94, p=.01, \eta^{2}=.06$, and a significant increase from the third to the last session, $F(1,95)=12.97$, $M S E=0.80, p<.003, \eta^{2}=.12$. The initial performance loss was probably due to the switch from standard assessments with fixed list lengths to an adaptive procedure that is based on errorless performance. $^{4}$

To document the magnitude and frequency of practice-related gains, research participants were categorized into two groups: individuals with (a) a gain of less than two words and (b) a gain of two or more words between the second and the last session. Despite its admittedly arbitrary nature, we chose this cutoff point because a performance gain of less than two words corresponds to a gain that can be expected by mere retesting without any practicerelated intervention and, thus, cannot be interpreted in terms of practice-induced improvement (see Verhaeghen et al., 1992). ${ }^{5}$

Only 14 participants (15\%) improved their performance by two or more words during training. Further analyses revealed that these 14 individuals differed from the other participants $(n=82)$ in that they were able to profit more from instruction in MoL. Thus, performance level of both groups did not differ at baseline assessment (mean word recall $=3.29$ for $n=82$ and 3.94 for $n=14$, Kruskal-Wallis $H$ value $=3.46, p>.05)$, but did differ significantly at Posttest I (mean recall $=6.66$ words for $n=82$ and 9.66 words for $n=14$, Kruskal-Wallis $H$ value $=10.84, p<$ .01 ) and at Posttest II (mean recall $=7.47$ words for $n=82$ and 10.87 words for $n=14$, Kruskal-Wallis $H$ value $=14.39, p<$ $.01)$. With respect to other individual characteristics such as chronological age, sociobiographical status, and current cognitive ability level, the only significant difference was found for performance levels in speed (mean level in speed $=56.25$ for $n=82$ and 62.18 for $n=14$, Kruskal-Wallis $H$ value $=6.89, p<.01$ ).

\section{Relations Between Frequency of Strategy Use and Performance in MoL}

In the following analyses we explored the relation between frequency of strategy use and performance with the MoL throughout the training study. First, we computed an MoL strategy utilization composite score reflecting the average frequency of $\mathrm{MoL}$ utilization on the basis of tutor-provided ratings from the third to the eighth sessions. Second, participants were classified into two groups on the basis of tutor-provided ratings concerning the frequency of correct strategy use: (a) frequent users of MoL (being rated as using MoL for "all words" or "more than half of the words") and (b) infrequent users (being rated as using $\mathrm{MoL}$ correctly for only "half of the words," "less than half of the words," and "not at all").

As can be seen in Table 3, correlations between the strategy utilization composite and Posttest II performance $(r=.74, p<$ $.01)$ as well as learning gain $(r=.64, p<.01)$ were high. These findings indicate that memory plasticity with $\mathrm{MoL}$ was indeed significantly higher for those using MoL more frequently than for those using it less frequently. Classification by frequency of use showed that the percentage of frequent users increased from $48 \%$ $(n=46)$ after instruction, to $59 \%$ at the first, $57 \%$ at the second, $67 \%$ at the third, $64 \%$ at the fourth practice session, and $66 \%$ at Posttest II. Across all sessions, only 5 or less than 5 individuals fell into the category of "not using the MoL at all."

In a next step we explored how the ability to optimize performance during the adaptive practice phase was related to frequency of strategy utilization. As reported previously, the majority of participants in very old age $(57 \%)$ used MoL frequently at the second practice session, but only a minority of participants (15\%) could improve their performance by a meaningful amount; that is, by two or more words during practice (see previous arguments). As expected, the minority of participants who had a gain of two or more words between the second and the last practice session were rated as using MoL frequently. Interestingly, however, $76 \%$ of the frequent MoL users $(n=42)$ were not able to increase their memory performance by two or more words during the adaptive training procedure, even though they were rated as frequently using the mnemonic technique at the beginning of the practice phase. The computation of a repeated measure ANOVA with test session (pretest, Posttest I) as the within-subject variable revealed that these 42 individuals indeed showed significant increases in memory performance after instruction in the mnemonic technique, $F(1,141)=124.96, M S E=3.08, p<.01, \eta^{2}=.75$. They increased their recall from 4.01 words to 8.29 words after instruction. Thus, these individuals seemed to have acquired MoL to some extent, given that they were able to improve their memory performance after instruction. Nevertheless, they were not able to optimize the use of this technique during adaptive training. In summary, these results suggest that, at least in very old age, frequent strategy use is a necessary but not a sufficient condition for practice-related optimization of memory performance.

\section{Magnification of Age Differences During Practice}

Because of ceiling effects at both posttests for young adults, age-related differences in memory plasticity are better reflected in age differences observed at the end of adaptive practice compared with initial (untrained) performance. Thus, effects of adult age differences were analyzed with an Age Group (young, very old) $\times$ Session (pretest, practice IV) ANOVA, with repeated measures on the second variable. Young adults recalled more words than the very old, $F(1,114)=148.47, M S E=22.42, p<.01, \eta^{2}=.57$, memory performance was higher at the fourth practice session than at baseline assessment, $F(1,114)=212.51, M S E=9.17, p<.01$, $\eta^{2}=.65$, and the young adults benefited significantly more from instruction and practice in MoL than the participants in very old age, Age $\times$ Session, $F(1,114)=40.32, M S E=9.17, p<.01$, $\eta^{2}=.26$. Furthermore, the shape of the learning function in younger adults was different from the shape in older adults. Results of a repeated measure ANOVA with practice session (Practice I to Practice IV) as the within-subject variable displayed a significant linear trend, $F(1,19)=52.05, M S E=5.92, p<.01$, $\eta^{2}=.73$, but also a marginally significant quadratic trend, $F(1$, 19) $=6.64, M S E=0.88, p<.05, \eta^{2}=.26$, suggesting a flattening of the acquisition function. Mean performance level of

\footnotetext{
${ }^{4}$ To illustrate, it is easier to correctly remember 11 words out of 16 words (maximum list length in Posttest I), or 69\% correctly, than to recall 11 out of 11 words, or $100 \%$. Note, however, that this change in practice format was not accompanied by a request to change the mnemonic strategy, nor did it require such a switch. As before, participants were asked to adhere to the principles of MoL taught in the instruction.

${ }^{5}$ A learning gain of two words corresponds to an increase of $0.44 S D$ relative to second practice session $(2 / 4.47=0.44)$. According to the meta-analysis of Verhaeghen et al. (1992), a learning gain of four tenths of a standard deviation is what can be expected by mere retesting.
} 
Table 3

Correlations of Predictor Measures and Memory Performance in Test and Practice Sessions for the Very Old Participants

\begin{tabular}{|c|c|c|c|c|c|c|c|c|c|c|c|c|c|}
\hline Predictor/Session & $1 \mathrm{a}$ & $2 \mathrm{a}$ & $3 \mathrm{a}$ & $4 \mathrm{a}$ & $1 b$ & $2 b$ & $3 b$ & $4 \mathrm{~b}$ & 5 & 6 & 7 & 8 & Age \\
\hline 1a. Memory $\left(\mathrm{T}_{1}\right)$ & - & & & & & & & & & & & & -.11 \\
\hline 2a. Speed $\left(T_{1}\right)$ & $.40^{* *}$ & - & & & & & & & & & & & $-.22 *$ \\
\hline 3a. Fluency $\left(\mathrm{T}_{1}\right)$ & $.43^{* *}$ & $.47 * *$ & - & & & & & & & & & & -.12 \\
\hline 4a. Knowledge $\left(\mathrm{T}_{1}\right)$ & $.45^{* * *}$ & $.35^{* *}$ & $.51 * *$ & - & & & & & & & & & -.03 \\
\hline 1b. Memory $\left(\mathrm{T}_{4}\right)$ & $.73^{* *}$ & & & & - & & & & & & & & -.15 \\
\hline 2b. Speed $\left(T_{4}\right)$ & $.36^{* * *}$ & $.76^{* *}$ & & & $.31 * *$ & - & & & & & & & $-.38 * *$ \\
\hline 3b. Fluency $\left(\mathrm{T}_{4}\right)$ & $.43^{* *}$ & $.42 * *$ & $.71 * *$ & & $.55^{* *}$ & $.43^{* *}$ & - & & & & & & $-.21 *$ \\
\hline 4b. Knowledge $\left(\mathrm{T}_{4}\right)$ & $.47 * *$ & $.32 * *$ & $.56^{* *}$ & $.82 * *$ & $.51 * *$ & $.23^{*}$ & $.43 * *$ & - & & & & & -.05 \\
\hline 5. Education $\left(\mathrm{T}_{1}\right)$ & .19 & $.34 * *$ & $.28 * *$ & $.38 * *$ & .09 & $.25^{*}$ & $.25^{*}$ & $.34 * *$ & - & & & & -.07 \\
\hline 6. Social class $\left(T_{1}\right)$ & .10 & $.21 *$ & .17 & $.33 * *$ & .12 & .17 & .09 & $.30 * *$ & $.46^{* *}$ & - & & & .01 \\
\hline 7. Income $\left(\mathrm{T}_{4}\right)$ & .10 & .18 & .09 & $.33 * *$ & .05 & $.20 *$ & .15 & $.29 * *$ & $.55^{* *}$ & $.33 * *$ & - & & -.10 \\
\hline 8. MoL strategy use & $.27 * *$ & $.25^{*}$ & $.30^{* *}$ & .15 & $.39 * *$ & $.37 * *$ & $.40 * *$ & $.25^{*}$ & -.04 & .04 & -.05 & - & -.16 \\
\hline \multicolumn{14}{|l|}{ MoL Performance } \\
\hline 1. Session (Pretest) & $.60^{* *}$ & $.43 * *$ & $.37 * *$ & $.47 * *$ & $.67 * *$ & $.36^{* *}$ & $.50 * *$ & $.49 * *$ & $.20 *$ & .16 & $.21 *$ & $.35^{* *}$ & $-.24 *$ \\
\hline 3. Session (Posttest I) & $.52 * *$ & $.42 * *$ & $.31^{* *}$ & $.32 * *$ & $.58 * *$ & $.52 * *$ & $.51 * *$ & $.38 * *$ & .10 & .05 & .11 & $.69 * *$ & $-.25^{*}$ \\
\hline 4. Session (Practice I) & $.52^{*}$ & $.44 *$ & $.37 * *$ & $.32 * *$ & $.58 *$ & $.52 * *$ & $.54 * *$ & $.37 * *$ & .08 & .07 & .10 & $.68 * *$ & $-.26^{* *}$ \\
\hline 5. Session (Practice II) & $.53^{* *}$ & $.40 * *$ & $.37 * *$ & $.29 * *$ & $.56^{* *}$ & $.48 * *$ & $.53 * *$ & $.32 * *$ & .07 & .10 & .08 & $.68 * *$ & $-.23^{*}$ \\
\hline 6. Session (Practice III) & $.53^{* *}$ & $.42 * *$ & $.36^{* *}$ & $.30 * *$ & $.57 * *$ & $.49^{* *}$ & $.54 * *$ & $.33 * *$ & .06 & .07 & .06 & $.68 * *$ & $-.24 *$ \\
\hline 7. Session (Practice IV) & $.52 * *$ & $.41 * *$ & $.34 * *$ & $.28 * *$ & $.55^{* *}$ & $.49^{* *}$ & $.51 * *$ & $.30 * *$ & .07 .07 & .08 & .06 & $.68 * *$ & $-.21 *$ \\
\hline 8. Session (Posttest II) & $.52 * *$ & $.38 * *$ & $.31^{* *}$ & $.27 * *$ & $.55^{* *}$ & $.49 * *$ & $.50 * *$ & $.35 * *$ & .03 & .01 & .07 & $.74 * *$ & -.20 \\
\hline Gain (Posttest II-Pretest) & .14 & .11 & .07 & -.06 & .12 & $.30 * *$ & $.20 *$ & -.01 & -.12 & -.12 & -.08 & $.64 * *$ & -.04 \\
\hline
\end{tabular}

Note. MoL strategy use refers to a composite score reflecting the average frequency of correct strategy use based on tutor-provided ratings. $N=96$, age range $=75-101$ years. $\mathrm{T}=$ time; $\mathrm{MoL}=$ Method of Loci.

$* p<.05 . \quad * * p<.01$.

young adults was $2.85 S D$ above the performance level of the very old participants at the last practice session: (21.09 - 7.72) / $4.69=2.85 S D$.

\section{Correlates of Memory Plasticity in Very Old Age}

\section{Prediction of Memory Performance by Current Status} $\left(T_{4}\right)$

This section reports results on the predictability of individual differences in memory plasticity in very old age using variables assessed on average 6.43 months prior to training at the fourth measurement occasion of BASE (1997-1998). The zero-order correlations of the predictor variables are displayed in Table 3.

Chronological age. As can be seen in Table 3, observed age relations within the very old sample were either small or insignificant. Neither the age relations to performance level at Posttest II $(r=-.20, p>.05)$ nor to gain reached statistical significance $(r=$ $-.04, p>.05)$. The correlation between age and memory performance at pretest and the correlation after instruction at Posttest I were significant but small (pretest: $r=-.24, p<.05$; Posttest I: $r=-.25, p<.05)$.

Predictive relations of perceptual speed, word knowledge, and sociobiographical background variables. The following analyses focus on perceptual speed (representing the fluid mechanics) versus knowledge (representing the crystallized pragmatics) as $\mathrm{T}_{4}$ predictors of MoL performance. Moreover, we report the predictive relations of sociobiographical variables to the plasticity measures.

As can be seen in Table 3, perceptual speed $\left(\mathrm{T}_{4}\right)$ showed a significant negative relation to age $(r=-.38, p<.01)$, whereas knowledge was unrelated to age $(r=-.05, n s)$. Perceptual speed accounted for $24.3 \%$ of the variance in $\mathrm{MoL}$ performance at Posttest II performance, and knowledge accounted for $12.3 \%$; this difference was not statistically reliable, $z=1.25, p=.11$. Individual differences in perceptual speed were more strongly related to individual differences in learning gain than individual differences in knowledge, $z=2.45, p<.01$.

As can be seen in Table 3 , the predictive power of perceptual speed increased with training, whereas the importance of knowledge decreased over the course of the study. For perceptual speed, the increase in predictive power of MoL performance was statistically reliable from pretest to Posttest $\mathrm{I}, z=1.96, p<.05$, but not from pretest to Posttest II, $z=1.58, p=.06$. For knowledge, the loss of predictive power of MoL performance was not significant from pretest to Posttest I, $z=1.43, p=.08$, but it was from pretest to Posttest II, $z=1.70, p<.05$.

Results of four multiple regression analyses of memory performance on the three sociobiographical variables revealed that the set of sociobiographical variables jointly accounted for $5.9 \%$ of the variance in MoL performance at pretest, $1.6 \%$ at Posttest I, $0.6 \%$ at Posttest II, and $2.1 \%$ in gain. Even though none of the predictive contributions reached significance, the predictive pattern pointed in the expected direction. Thus, the three sociobiographical variables lost predictive power from pretest to Posttest II in a onetailed test, $z=1.86, p<.05$.

Pattern of relations between cognitive abilities and memory plasticity. The overall correlations of the four cognitive abilities at $\mathrm{T}_{4}$ with MoL performance were uniformly high. As displayed in Table 4 , the four cognitive abilities jointly predicted between $43 \%$ and $51 \%$ at pre- and posttest performances, respectively, and $11 \%$ in gain. Table 4 also shows unique effects of each of the four cognitive variables after controlling for individual differences in the other three abilities. At pretest, memory was the only ability showing a statistically significant unique effect. After instruction and practice, the unique effect of perceptual speed increased and reached a magnitude similar to the unique effect displayed by 
Table 4

Results of Four Multiple Regression Analyses of Memory Performance on Concurrent Cognitive Status and Unique Effects of Each of the Four Cognitive Abilities

\begin{tabular}{lllll}
\hline \multicolumn{1}{c}{ Predictors at $\mathrm{T}_{4}$} & Pretest & Posttest I & Posttest II & Gain \\
\hline Memory & $0.49 * *$ & $0.37 * *$ & $0.35^{* *}$ & 0.03 \\
Speed & 0.13 & $0.32^{* *}$ & $0.30^{* *}$ & $0.26^{*}$ \\
Fluency & 0.09 & 0.14 & 0.16 & 0.12 \\
Knowledge & 0.17 & 0.05 & 0.02 & 0.11 \\
$R^{2}$ & $0.51^{* *}$ & $0.48^{* *}$ & $0.43^{* *}$ & $0.11^{*}$ \\
$\Delta R^{2}$ due Memory & $0.14^{* *}$ & $0.08^{* *}$ & $0.07 * *$ & 0.00 \\
$\Delta R^{2}$ due Speed & 0.01 & $0.08^{* *}$ & $0.07 * *$ & $0.06^{*}$ \\
$\Delta R^{2}$ due Fluency & 0.00 & 0.01 & 0.01 & 0.01 \\
$\Delta R^{2}$ due Knowledge & 0.02 & 0.00 & 0.00 & 0.00 \\
\hline
\end{tabular}

Note. Values are standardized regression coefficients $(\beta) . \Delta R^{2}$ represents unique variance components; that is, the change in $R^{2}$ that was due to the respective cognitive ability after controlling for the other three abilities. $\mathrm{T}=$ time

$* p<.05 . \quad * * p<.01$.

memory. With respect to gain, only perceptual speed showed statistically reliable unique effects.

\section{Prediction of Memory Performance by Six-Year Longitudinal Antecedents}

This section reports results on the prediction of individual differences in memory plasticity in very old age by longitudinal antecedents in cognitive functioning. First, we explore predictive relations between initial cognitive status $\left(\mathrm{T}_{1}\right)$ and 6-year preceding longitudinal change in cognition and the memory performance measures before and after instruction and practice with MoL. In a second step, we tested whether measures of differential longitudinal change predicted additional variance after measures of current status $\left(\mathrm{T}_{4}\right)$ were considered.

Before testing our hypothesis, we determined whether the four cognitive abilities displayed enough individual differences in longitudinal change in our longitudinal sample $(n=96)$ to serve as useful predictors for memory plasticity using latent growth modeling (LGM; e.g., Lindenberger \& Ghisletta, in press). Specifically, we examined the significance of the variance of the change factors comparing two linear latent growth models differing only with respect to the variance of the slope factor (fixed to zero vs. freely estimated). The difference in fit between the two models proved to be significant only for speed measures: difference in $\chi^{2}(1, N=96)=5$. Consequently, we decided to restrict our analyses to the speed measures.

Prediction by initial status and longitudinal differential change. In Model 1 of Table 5, the results of four hierarchical regression analyses are summarized. In a first step, measures of initial status $\left(T_{1}\right)$ in speed were entered. Measures of current status $\left(T_{4}\right)$ were entered in a second step. For each analysis, standardized regression coefficients $(\beta), R^{2}$, and the incremental $R^{2}$ after adding the $\mathrm{T}_{4}$ variable are displayed. The magnitude of change in $R^{2}$ displays how much variance can be predicted by differential longitudinal change over a mean period of 6 years that is not accounted for by initial status. Note that these values correspond to residualized gain scores; that is, change scores residualized on the first measurement occasion.
Table 5

Results of Eight Hierarchical Regression Analyses of Memory Performance on Initial $\left(T_{1}\right)$ and Concurrent $\left(T_{4}\right)$ Level in Speed

\begin{tabular}{lllll}
\hline \multicolumn{1}{c}{ Predictor } & Pretest & Posttest I & Posttest II & Gain \\
\hline \multicolumn{4}{c}{ Model 1 } \\
Step 1 & & & & \\
$\quad$ Speed $\left(\mathrm{T}_{1}\right)$ & $0.43^{* *}$ & $0.42^{* *}$ & $0.38^{* * *}$ & 0.11 \\
$R^{2}$ & $0.19^{* *}$ & $0.17^{* *}$ & $0.15^{* *}$ & 0.01 \\
Step 2 & & & & \\
$\quad$ Speed $\left(\mathrm{T}_{1}\right)$ & $0.37^{*}$ & 0.05 & 0.02 & -0.28 \\
$\quad$ Speed $\left(\mathrm{T}_{4}\right)$ & 0.08 & $0.47^{* *}$ & $0.47^{* * *}$ & $0.52^{* *}$ \\
$\Delta R^{2}$ due to Speed $\left(\mathrm{T}_{4}\right)$ & 0.00 & $0.10^{* *}$ & $0.09^{* *}$ & $0.11^{* *}$ \\
\hline & & & &
\end{tabular}

Model 2

Step 1

\begin{tabular}{lllll}
$\quad$ Speed $\left(\mathrm{T}_{4}\right)$ & $0.36^{* *}$ & $0.52^{* *}$ & $0.49 * *$ & 0.30 \\
$R^{2}$ & $0.14^{* *}$ & $0.27^{* *}$ & $0.24 * *$ & $0.09^{* *}$ \\
Step 2 & & & & \\
$\quad$ Speed $\left(\mathrm{T}_{4}\right)$ & 0.08 & $0.47^{* *}$ & $0.47^{* *}$ & $0.52^{* *}$ \\
$\quad$ Speed $\left(\mathrm{T}_{1}\right)$ & $0.37^{*}$ & 0.05 & 0.02 & -0.28 \\
$\Delta R^{2}$ due to Speed $\left(\mathrm{T}_{1}\right)$ & $0.05^{*}$ & 0.00 & 0.00 & 0.03 \\
\hline
\end{tabular}

Note. Values are standardized regression coefficients $(\beta) . \mathrm{T}=$ time. $* p<.05$. *** $p<.01$.

As expected, differential change in perceptual speed over a mean period of 6 years and individual differences in memory plasticity were positively related: Participants who had a greater longitudinal loss in speed showed lower maximum performance level and less learning gain. Specifically, differential longitudinal change explained $9 \%-10 \%$ of the variance in the posttest performances and $11 \%$ in gain. Also, while measures of initial status in speed explained $19 \%$ of baseline performance at pretest, longitudinal differential change in speed did not explain any additional variance in baseline performance (see Figure 1). The significant effect of differential longitudinal change in speed was revealed only after acquisition and practice in MoL. With respect to learning gain, the pattern was reversed: Initial status in speed at $\mathrm{T}_{1}$ did not explain any variance in training success, but differential lon-

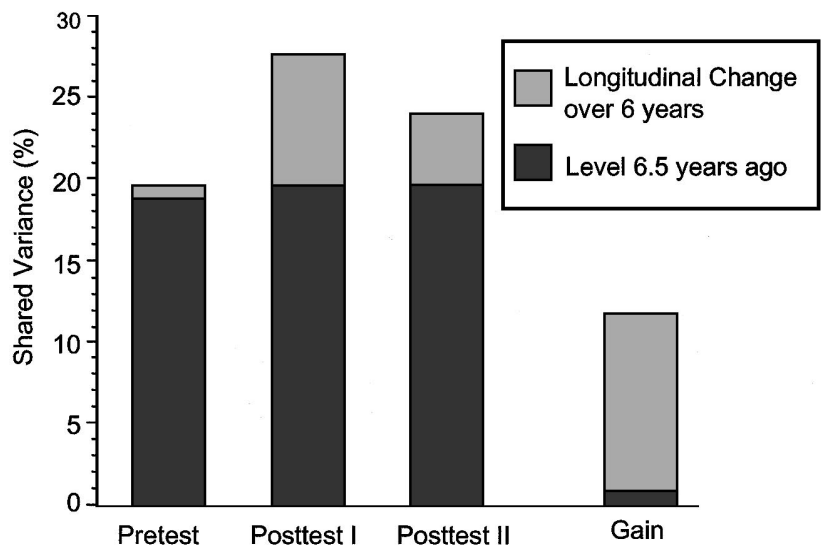

Figure 1. Individual differences in plasticity of episodic memory performance in very old age: Divergent predictive patterns of initial level at $T_{1}$ and subsequent 6-year longitudinal change in perceptual speed. Results are based on four separate hierarchical linear regression analyses. Gray shading represents unique prediction component of change. $\mathrm{T}=$ time. 
gitudinal change (loss) measures explained $11 \%$ of the variance in the simple gain score.

Prediction by current status and longitudinal differential change. In Model 2 of Table 5, we tested the hypothesis that consideration of differential 6-year longitudinal change adds some additional predictive information relevant to plasticity that was not captured by measures of current ability status. Analogous to the analyses in Model 1, we conducted four hierarchical regression analyses. This time, measures of current status $\left(\mathrm{T}_{4}\right)$ in speed were entered in a first step and measures of initial status in speed in a second step.

These analyses revealed that concurrent data on cognitive status were sufficient to predict cognitive training outcomes with the present set of variables. Thus, after measures of current speed status were entered into the regression analysis, measures of preceding longitudinal change in speed did not explain additional variance in either posttest performances or learning gain.

\section{Discussion}

Our study had two main goals. The first was to describe memory plasticity for "new" learning of a fairly complex cognitive skill (MoL) in very old age; that is, at an age range of 75-100 years and above. The second goal was to explain individual differences in plasticity in this age group using ability and sociocultural background factors. Besides measures of current ability level, we also considered longitudinal antecedents of memory plasticity as predictors.

\section{The Nature of Cognitive Plasticity in Very Old Age}

Memory plasticity with MoL is still preserved in very old age, but to a very reduced degree. After a short instruction phase, participants in very old age improved their MoL related memory performance from an average of 3.39-7.10 words (1.62 SD of baseline performance). These performance gains are far from negligible, but they are relatively small compared with the amount of MoL memory plasticity observed in healthy older adults aged 60-80 years. For instance, the young-old adults in a study by Kliegl et al. (1990) reached an average performance level of 12.6 words after instruction (3.06 SD of their baseline performance) under more difficult task conditions. In line with the observation of relatively low performance levels after instruction, analyses of MoL ratings by the tutors indicated that a large part of the participants in very old age did not apply the mnemonic technique consistently after instruction and that memory performance with MoL as well as the size of the learning gain was closely tied to the frequency of strategy use (for similar results, see Verhaeghen \& Marcoen, 1996). Hence, evidence for the effectiveness of MoL, repeatedly found in training studies with healthy older adults, could at least partially be extended to very old age, but the amount of plasticity elicited through instruction in MoL was substantially reduced as the life span theory on cognitive plasticity suggests (P. B. Baltes, 1987).

The present findings also suggest that the potential to further refine and optimize the use of the acquired technique during subsequent practice is even more strongly reduced in the last period of life than the ability to profit from mnemonic instruction. Thus, surprisingly, the practice function was basically flat, and post hoc analyses demonstrated that the majority (85\%) of the 75 to 101-year-old participants were not able to improve their memory performance by any substantive amount during adaptive practice. This finding cannot simply be explained by the fact that participants in very old age did not adhere to MoL during practice. Even though the majority of the participants were rated to use MoL frequently in the second practice session, $76 \%$ of these frequent users were unable to improve their performance during adaptive practice, even though they had shown reliable learning gains after instruction. Thus, results seem to suggest that frequent use of the mnemonic technique is a necessary but not a sufficient condition for practice-related performance improvement. Furthermore, the observation that young adults were capable of continuously improving their memory performances throughout all four sessions of adaptive practice suggests that the absence of training gains in very old age is not purely an artifact of the specific adaptive format of the used practice procedure. Given the age difference in learning functions (see Table 2), it seems likely that further practice would have led to further magnification of age differences. The observed magnification of age differences during practice is in accordance with previous findings of memory training studies with young-old adults (P. B. Baltes \& Kliegl, 1992; Kliegl et al., 1990; Rebok \& Balcerak, 1989; Rose \& Yesavage, 1983; Verhaeghen \& Marcoen, 1996) and speaks for a substantial age-related reduction in cognitive plasticity.

The widespread inability to optimize performance through practice observed in the present study seems at odds with the agecomparative skill learning literature (e.g., P. B. Baltes \& Kliegl, 1992; Hertzog, Cooper, \& Fisk, 1996; Rogers, Fisk, \& Hertzog, 1994). Clearly, our findings may be specific to the special features of the task. For instance, the operational definition of practice progress in the present study refers to the ability to continuously improve performance under the precondition of perfect performance. Perhaps, the production of perfect (errorless) performance poses special problems to very old but not to young adults. This possibility would be consistent with theoretical propositions and recent formal simulations of cognitive aging that posit a general decrease in a signal:noise ratio that is due to deficient neuromodulation with age (Li, Lindenberger, \& Sikström, 2001; Welford, 1965). It cannot be excluded that alternative practice procedures such as a longer instruction phase, alternative modes of feedback, and a relaxation of practice criteria (e.g., Kliegl, Philipp, Luckner, \& Krampe, 2001) would induce performance improvements in advanced old age. Despite these qualifications, it seems safe to draw the conclusion that efforts at optimization in the domain of episodic memory functioning are severely restricted by age-related losses in very old age, given that optimization and the production of errorless performance are intimately related.

\section{The Reduction of Cognitive Plasticity: Explanation and Open Questions}

The present results point to a central role of measures of perceptual speed in predicting memory plasticity (see also Verhaeghen \& Marcoen, 1996). Whereas not surprisingly, memory ability was found to be the best predictor of memory performance at baseline assessment (and the only cognitive ability explaining unique additional variance in pretest), perceptual speed gained importance after mnemonic skill acquisition and explained equal shares of unique variance as the memory measures. Thus, perceptual speed was the best predictor of individual differences in 
learning gain, in terms of both unique and simple (zero-order) variance components. Moreover, the 14 individuals who were able to further improve their performance throughout practice differed from the remaining group only in regard to their level in perceptual speed. Finally, analyses concerning longitudinal antecedents of memory plasticity suggest that measures of 6-year longitudinal change in perceptual speed represent sensitive indicators of aging mechanisms associated with the reduction of plasticity.

The increase in predictive power of perceptual speed during training corresponds to previous findings with young and old adults showing an increase of predictive importance of cognitive abilities from the broad fluid-ability domain in the course of skill acquisition (cf. Ackerman \& Cianciolo, 2000; Kliegl et al., 1990; Labouvie, Frohring, Baltes, \& Goulet, 1973; Rogers et al., 1994). In addition, measures of speed have repeatedly been found to be closely linked to age-related individual differences in episodic memory functioning and other aspects of fluid intelligence (Bryan \& Luszcz, 1996; Lindenberger et al., 1993; Salthouse, 1996; Verhaeghen \& Salthouse, 1997) and have been interpreted as prime indicators of age-related differences in (a) the speed of mental processing rate (see Salthouse, 1985, 1996, for a discussion about a possible link between speed-of-processing rate and neuronal integrity; see also Cerella, 1990), (b) the mechanic fluid abilities (Bäckman et al., 1998; Hill, Stigsdotter Neely, \& Bäckman, 1997; Kliegl et al., 1990; Lindenberger \& Baltes, 1997), and (c) the biological integrity of cerebral functions in general (e.g., Luszcz \& Bryan, 1999). The present study adds to the empirical importance of the speed measures but cannot differentiate among these different interpretations. Clearly, the inclusion of additional predictor measures would have been useful (e.g., measures of reasoning as alternative prototypical and nonambiguous markers of the broad fluid domain or simple reaction time measures).

The assumption that testing-the-limits or dynamic testing procedures (for an overview, see Grigorenko \& Sternberg, 1998) lead to a more precise assessment of the latent capacity of an aging individual than standard one-time assessments is underlined by the existence of learning-dependent changes in predictive relations. Thus, the increase in predictive importance of perceptual speed with the simultaneous decrease in predictive power of sociobiographical variables and knowledge during training is in line with the assumption that instruction and extensive practice in a new strategy reduce the impact of task-specific performance factors such as test-taking skills and familiarity with the test situation (differences reflected in measures of knowledge and socioeconomic status). In addition, instruction and practice induce the use of more general cognitive resources (M. M. Baltes \& Kindermann, 1985; Kliegl \& Baltes, 1987; Kliegl et al., 1990). The usefulness of the testing-the-limits approach is further corroborated through the finding that individual differences in 6-year changes in perceptual speed were revealed only after mnemonic skill learning and not through one-time assessment at baseline alone. Thus, when predictors of initial status and 6-year longitudinal change in speed were considered alone (i.e., without the $\mathrm{T}_{4}$ measures; see Figure 1), microgenetic change (individual differences in learning gain) was predicted only by macrogenetic change measures in perceptual speed and not by initial level in perceptual speed. In an analogous fashion, level at baseline in pretest was predicted only by initial level and not by macrogenetic change.

In line with this finding of specific associations between macroand microgenetic change measures and relying on notions of dynamic systems theory and general developmental theories (e.g., P. B. Baltes et al., 1988; Elman et al., 1996; Lindenberger \& Baltes, 1995), we expected that ontogenetic trajectories contain plasticity-related information over and above concurrent status measures. However, at least in the present data set and with the present statistical analyses, measures of 6-year longitudinal change in speed could not account for additional variance in plasticity measures after current status $\left(\mathrm{T}_{4}\right)$ in perceptual speed was taken into account. Taken together, the present set of analyses suggests (a) that earlier information on the cognitive history of individuals did not add anything beyond information about current status in explaining individual differences in memory plasticity (see Model 2 of Table 5) but (b) that the component associated with age-related changes in the current status of a person probably is most strongly associated with individual differences in training success (see Model 1 of Table 5).

\section{Effects of Sample Selectivity}

When interpreting the present findings, effects of sample selectivity need to be considered. Results were obtained with a sample of individuals who had survived into very old age and were willing and able to participate in a longitudinal study. Accordingly, selectivity analyses revealed that a positive selection bias was present in the present sample. ${ }^{6}$ The magnitude of total selectivity in a composite index of intellectual functioning in the present sample amounted to $0.89 S D$ units. Sixty-one percent of the overall observable selectivity was associated with mortality (0.54 SD), 39\% with experimental selectivity $(0.35 S D)$. According to conventions (e.g., Cohen, 1977), observed selectivity corresponded to a medium-sized effect. In addition, the magnitude of selectivity correlated positively with age. Specifically, selectivity amounted to $0.36 S D$ in the younger age group and to $1.16 S D$ in the old group.

Three implications of observed selectivity effects are especially important: (a) the positively selected nature of the sample suggests that the amount of memory plasticity obtained in this study overestimates the average level of plasticity in the population; (b) with respect to predictions of memory plasticity through longitudinal change measures, the average amount of longitudinal change in very old age is underestimated in the present longitudinal sample because participants with greater losses in performance tend to drop out earlier (see Siegler \& Botwinick, 1979; Singer et al., 2003). Because variability of longitudinal change measures is reduced through selection, the overall correlational link between macro- and microgenetic change is reduced; and (c) the presence of age-correlated selectivity effects in the longitudinal sample implies that observed age relations are attenuated relative to ageperformance relations in the population. This may explain the lack

\footnotetext{
${ }^{6}$ The computation of selectivity effects was carried out for the total sample as well as for two different age groups: the participants under 80 and participants at and above 80 years of age. Furthermore, total selectivity was decomposed into two selectivity components: (a) a mortalityassociated component, or the extent to which individuals still alive at the beginning of the training study ( $n=184$; January, 1998) differ from the parent sample of BASE $(N=516 ; 1990-1993)$, and (b) an experimental component, or the extent to which the present training sample ( $n=96$; 1998) differs from the survivors (for details on computation of selectivity effects, see Lindenberger, Singer, \& Baltes, 2002).
} 
of age differences in plasticity within the present sample of very old individuals, which stands in contrast both to earlier findings (Gratzinger, Sheikh, Friedman, \& Yesavage, 1990; Verhaeghen et al., 1992; Yesavage et al., 1990) and to the observed magnification of age differences during training between young and very old participants.

\section{References}

Ackerman, P. L., \& Cianciolo, A. T. (2000). Cognitive, perceptual-speed, and psychomotor determinants of individual differences during skill acquisition. Journal of Experimental Psychology: Applied, 6, 259-290.

American Psychiatric Association. (1987). Diagnostic and statistical manual of mental disorders (Rev. ed.). Washington, DC: Author.

Bäckman, L., Hill, R. D., Herlitz, A., Robins Wahlin, T. B., Wahlin, A., \& Winblad, B. (1998). Predictors of change in verbal and nonverbal episodic memory performance in a 2-year longitudinal study of optimally healthy very old adults. Journal of Mental Health and Aging, 4, 139-154.

Bäckman, L., Small, B. J., Wahlin, A., \& Larsson, M. (2000). Cognitive functioning in very old age. In F. I. M. Craik \& T. A. Salthouse (Eds.), Handbook of aging and cognition (2nd ed., pp. 499-558). Hillsdale, NJ: Erlbaum.

Baltes, M. M. (1998). The psychiatry of the oldest-old: The fourth age. Current Opinion in Psychology, 11, 411-415.

Baltes, M. M., \& Baltes, P. B. (1997). Normal versus pathological cognitive functioning in old age: Plasticity and testing-the-limits of cognitive/ brain reserve capacity. In F. Forette, Y. Christen, \& F. Boller (Eds.), Démences et longévité (pp. 77-101). Paris: Fondation Nationale de Gérontologie.

Baltes, M. M., \& Kindermann, T. (1985). Die Bedeutung der Plastizität für die klinische Beurteilung des Leistungsverhaltens im Alter [The significance of plasticity for clinical assessment of performance in old age]. In D. Bente, H. Coper, \& S. Kanowski (Eds.), Hirnorganische Psychosyndrome im Alter: Methoden zur Objektivierung pharmakotherapeutischer Wirkung (Vol. 2, pp. 171-184). Berlin: Springer.

Baltes, P. B. (1987). Theoretical propositions of life-span developmental psychology: On the dynamics between growth and decline. Developmental Psychology, 23, 611-626.

Baltes, P. B., \& Kliegl, R. (1992). Further testing of limits of cognitive plasticity: Negative age differences in a mnemonic skill are robust. Developmental Psychology, 28, 121-125.

Baltes, P. B., \& Lindenberger, U. (1988). On the range of cognitive plasticity in old age as a function of experience: 15 years of intervention research. Behavior Therapy, 19, 283-300.

Baltes, P. B., \& Mayer, K. U. (Eds.). (1999). The Berlin Aging Study: Aging from 70 to 100. New York: Cambridge University Press.

Baltes, P. B., Reese, H. W., \& Nesselroade, J. R. (1988). Life-span developmental psychology: Introduction to research methods. Hillsdale, NJ: Erlbaum.

Baltes, P. B., \& Willis, S. L. (1982). Plasticity and enhancement of intellectual functioning in old age: Penn State's Adult Development and Enrichment Project ADEPT. In F. I. M. Craik \& S. E. Trehub (Eds.), Aging and cognitive processes (pp. 353-389). New York: Plenum Press.

Baschek, I.-L., Bredenkamp, J., Öhrle, B., \& Wippich, W. (1977). Bestimmung der bildhaftigkeit (I), konkretheit (C) und der bedeutungshaftigkeit (m') von 800 Substantiven [Evaluation of imagery (I), concreteness (C) and meaning (M) of 800 nouns]. Zeitschrift für Experimentelle und Angewandte Psychologie, 32, 3-20.

Bower, G. H. (1970). Analysis of a mnemonic device. American Scientist, 58, 496-510.

Bryan, J., \& Luszcz, M. A. (1996). Speed of information processing as a mediator between age and free-recall performance. Psychology and Aging, 11, 3-9.

Camp, C. J. (1998). Memory intervention for normal and pathological older adults. Annual Review of Gerontology and Geriatrics, 18, 155189.

Carlson, J. S., \& Wiedl, K. H. (1978). Use of testing-the-limits procedures in the assessment of intellectual capabilities in children with learning difficulties. American Journal of Mental Deficiency, 82, 559-564.

Carroll, J. B. (1993). Human cognitive abilities. Cambridge, England: Cambridge University Press.

Cattell, R. B. (1971). Abilities: Their structure, growth, and action. Boston: Houghton Mifflin.

Cerella, J. (1990). Aging and information-processing rate. In J. E. Birren \& K. W. Schaie (Eds.), Handbook of the psychology of aging (pp. 201221). San Diego, CA: Academic Press.

Cohen, J. (1977). Statistical power analysis for the behavioral sciences (Rev. ed.). New York: Academic Press.

Cronbach, L. J., \& Furby, L. (1970). How we should measure "change"-Or should we? Psychological Bulletin, 74, 68-80.

Elman, J. L., Bates, E. A., Johnson, M. H., Karmiloff-Smith A., et al (1996). Rethinking innateness: A connectionist perspective on development. Cambridge, MA: MIT Press.

Folstein, M. F., Folstein, S. E., \& McHugh, P. R. (1975). Mini-mental state: A practical method for grading the cognitive state of patients for the clinician. Journal of Psychiatric Research, 12, 189-198.

Gratzinger, P., Sheikh, J. I., Friedman, L., \& Yesavage, J. A. (1990). Cognitive interventions to improve face-name recall: The role of personality trait differences. Developmental Psychology, 26, 889-893.

Grigorenko, E. L., \& Sternberg, R. J. (1998). Dynamic testing. Psychological Bulletin, 124, 75-111.

Guthke, J. (1992). Learning tests: The concept, main research findings, problems, and trends. Advances in Cognition and Educational Practice, 1A, 213-233.

Hertzog, C., Cooper, B. P., \& Fisk, A. D. (1996). Aging and individual differences in the development of skilled memory search performance. Psychology and Aging, 11, 497-520.

Hill, R. D., Stigsdotter Neely, A., \& Bäckman, L. (1997). Predictors of change on the Fuld Object Memory Evaluation in a two-year longitudinal study of optimally healthy very old adults. Aging \& Mental Health, 1, 140-148.

Horn, J. L. (1989). Models of intelligence. In R. L. Linn (Ed.), Intelligence: Measurement, theory, and public policy (pp. 29-73). Urbana, IL: University of Illinois Press.

Karmiloff-Smith, A. (1992). Beyond modularity: A developmental perspective on cognitive science. Cambridge, MA: MIT Press.

Kliegl, R., \& Baltes, P. B. (1987). Theory-guided analysis of mechanisms of development and aging mechanisms through testing-the-limits and research on expertise. In C. Schooler \& K. W. Schaie (Eds.), Cognitive functioning and social structure over the life course (pp. 95-119). Norwood, NJ: Ablex.

Kliegl, R., Philipp, D., Luckner, M., \& Krampe, R. (2001). Face memory skill acquisition. In N. Charness, D. C. Park, \& B. Sabel (Eds.), Communication, technology and aging: Opportunities and challenges for the future (pp. 169-186). New York: Springer.

Kliegl, R., Smith, J., \& Baltes, P. B. (1990). On the locus and process of magnification of age differences during mnemonic training. Developmental Psychology, 26, 894-904.

Labouvie, G. V., Frohring, W., Baltes, P. B., \& Goulet, L. R. (1973). Changing relationship between recall performance and abilities as a function of stage of learning and timing of recall. Journal of Educational Psychology, 64, 191-199.

Li, S.-C., Lindenberger, U., \& Sikström, S. (2001). Aging cognition: From neuromodulation to representation to cognition. Trends in Cognitive Science, 5, 479-486.

Lindenberger, U., \& Baltes, P. B. (1994). Sensory functioning and intelligence in old age: A strong connection. Psychology and Aging, 9, $339-355$.

Lindenberger, U., \& Baltes, P. B. (1995). Testing-the-limits and experi- 
mental simulation: Two methods to explicate the role of learning in development. Human Development, 38, 349-360.

Lindenberger, U., \& Baltes, P. B. (1997). Intellectual functioning in old and very old age: Cross-sectional results from the Berlin Aging Study. Psychology and Aging, 12, 410-432.

Lindenberger, U., \& Ghisletta, P. (in press). Modeling longitudinal changes in old age: From covariance sturctures to dynamic systems. In R. A. Dixon, L. Baechman, \& L.-G. Nilsson (Eds.), New frontiers in cognitive aging. Oxford, England: Oxford University Press.

Lindenberger, U., Mayr, U., \& Kliegl, R. (1993). Speed and intelligence in old age. Psychology and Aging, 8, 207-220.

Lindenberger, U., Singer, T., \& Baltes, P. B. (2002). Longitudinal selectivity in aging populations: Separating mortality-associated versus experimental components in the Berlin Aging Study (BASE). Journals of Gerontology. Series B, Psychological Sciences and Social Sciences, 57, P474-P482

Luszcz, M. A., \& Bryan, J. (1999). Toward understanding age-related memory loss in late adulthood. Gerontology, 45, 2-9.

Mayer, K. U., \& Wagner, M. (1996). Lebenslagen und soziale Ungleichheit im hohen Alter [Life conditions and social inequality in old age]. In K. U. Mayer \& P. B. Baltes (Eds.), Die Berliner Altersstudie (pp. 251-275). Berlin: Akademie Verlag.

Mayr, U., \& Kliegl, R. (2000). Complex semantic processing in old age: Does it stay or does it go? Psychology and Aging, 15, 29-43.

Paivio, A., Yuille, J. C., \& Madigan, S. A. (1968). Concreteness, imagery, and meaningfulness values for 925 nouns. Journal of Experimental Psychology (Monograph Suppl. 76, Pt. 2), 1-25.

Park, D. C., Smith, A. D., \& Cavanaugh, J. C. (1990). Metamemories of memory researchers. Memory \& Cognition, 18, 321-327.

Rebok, G. W., \& Balcerak, L. J. (1989). Memory self-efficacy and performance differences in young and old adults: The effect of mnemonic training. Developmental Psychology, 25, 714-721.

Rogers, W. A., Fisk, A. D., \& Hertzog, C. (1994). Do ability-performance relationships diffentiate age and practice effects in visual research? Journal of Experimental Psychology: Learning, Memory, and Cognition, 20, 710-738.

Rogosa, D., Brandt, D., \& Zimowski, M. (1982). A growth curve approach to the measurement of change. Psychological Bulletin, 92, 726-748.

Rose, T. L., \& Yesavage, J. A. (1983). Differential effects of a list-learning mnemonic in three age groups. Gerontology, 29, 293-298.

Salthouse, T. A. (1985). A theory of cognitive aging. Amsterdam: NorthHolland.

Salthouse, T. A. (1993). Speed and knowledge as determinants of adult age differences in verbal tasks. Journals of Gerontology, 48, P29-P36.

Salthouse, T. A. (1996). The processing-speed theory of adult age differences in cognition. Psychological Review, 103, 403-428.

Schaie, K. W. (1996). Adult intellectual development: The Seattle Longitudinal Study. New York: Cambridge University Press.

Schaie, K. W., \& Willis, S. L. (1986). Can decline in adult intellectual functioning be reversed? Developmental Psychology, 22, 223-232.
Siegler, I. C., \& Botwinick, J. (1979). A long-term longitudinal study of intellectual ability of older adults: The matter of selective subject attrition. Journal of Gerontology, 34, 242-245.

Singer, T., Verhaeghen, P., Ghisletta, P., Lindenberger, U., \& Baltes, P. B. (2003). The fate of cognition in very old age: Six-year longitudinal findings in the Berlin Aging Study (BASE). Psychology and Aging, 18, $318-331$.

Stigsdotter Neely, A. (1994). Memory training in late adulthood: Issues of maintenance, transfer and individual differences. Unpublished doctoral dissertation, Karolinska Institute and Stockholm Gerontology Research Center, Stockholm, Sweden.

Thompson, L. A., \& Kliegl, R. (1991). Adult age effects of plausibility on memory: The role of time constraints during encoding. Journal of Experimental Psychology: Learning, Memory, and Cognition, 17, 542555.

Vaupel, J. W., Carey, J. R., Christensen, K., Johnson, T. E., Yashin, A. I., Holm, N. V., et al. (1998). Biodemographic trajectories of longevity. Science, 280, 855-860.

Verhaeghen, P., \& Marcoen, A. (1996). On the mechanisms of plasticity in young and older adults after instruction in the method of loci: Evidence for an amplification model. Psychology and Aging, 11, 164-178.

Verhaeghen, P., Marcoen, A., \& Goossens, L. (1992). Improving memory performance in the aged through mnemonic training: A meta-analytic study. Psychology and Aging, 7, 242-251.

Verhaeghen, P., \& Salthouse, T. A. (1997). Meta-analyses of agecognition relations in adulthood: Estimates of linear and non-linear age effects and structural models. Psychological Bulletin, 122, 231-249.

Wagner, G., Motel, A., Spiess, K., \& Wagner, M. (1996). Wirtschaftliche Lage und wirtschaftliches Handeln alter Menschen [The economic situation and economic activity of the elderly]. In K. U. Mayer \& P. B. Baltes (Eds.), Die Berliner Altersstudie (pp. 277-300). Berlin: Akademie Verlag.

Wechsler, D. (1955). Wechsler Adult Intelligence Scale manual. New York: The Psychological Corporation.

Wechsler, D. (1982). Handanweisung zum Hamburg-WechslerIntelligenztest für Erwachsene (HAWIE). Bern, Germany: Huber.

Welford, A. T. (1965). Performance, biological mechanisms and age: A theoretical sketch. In T. Welford \& J. E. Birren (Eds.), Behavior, aging, and the nervous system (pp. 3-20). Springfield, IL: Thomas.

Willis, S. L., \& Nesselroade, C. S. (1990). Long-term effects of fluid ability training in old-old age. Developmental Psychology, 26, 905-910.

Yesavage, J. A. (1983). Imagery pretraining and memory training in the elderly. Gerontology, 29, 271-275.

Yesavage, J. A., Sheikh, J. I., Friedman, L., \& Tanke, E. D. (1990). Learning mnemonics: Roles of aging and subtle cognitive impairment. Psychology and Aging, 5, 133-137.

Received February 27, 2001

Revision received May 21, 2001

Accepted October 2, 2002 